\title{
CBMA [Chartae Burgundiae Medii Aevi] - VI. Les chartes bourguignonnes sous Philologic
}

Dijon, UMR 5594 Artehis, le 27 janvier 2012

Eliana Magnani et Marie-José Gasse-Grandjean

\section{(2) OpenEdition}

\section{Journals}

Édition électronique

URL : https://journals.openedition.org/cem/12047

DOI : $10.4000 /$ cem. 12047

ISSN : 1954-3093

Éditeur

Centre d'études médiévales Saint-Germain d'Auxerre

Édition imprimée

Pagination : 00

ISSN : 1623-5770

\section{Référence électronique}

Eliana Magnani et Marie-José Gasse-Grandjean, « CBMA [Chartae Burgundiae Medii Aevi] - VI. Les chartes bourguignonnes sous Philologic », Bulletin du centre d'études médiévales d'Auxerre / BUCEMA [En ligne], 15 | 2011, mis en ligne le 26 mars 2013, consulté le 22 septembre 2022. URL : http:// journals.openedition.org/cem/12047 ; DOI : https://doi.org/10.4000/cem.12047

Ce document a été généré automatiquement le 22 septembre 2022.

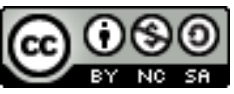

Creative Commons - Attribution - Pas d'Utilisation Commerciale - Partage dans les Mêmes Conditions 4.0 International - CC BY-NC-SA 4.0

https://creativecommons.org/licenses/by-nc-sa/4.0/ 


\title{
CBMA [Chartae Burgundiae Medii Aevi] - VI. Les chartes bourguignonnes sous Philologic
}

Dijon, UMR 5594 Artehis, le 27 janvier 2012

\author{
Eliana Magnani et Marie-José Gasse-Grandjean
}

1 Depuis l'été 2010, les chartes bourguignonnes réunies dans la base des CBMA peuvent être interrogées librement sur internet avec le logiciel Philologic [http://www.artehiscbma.eu/]. Il s'agit, actuellement, du seul corpus diplomatique étendu permettant, entre autres, la recherche de cooccurrences, un affichage par mot-clé, par distribution chronologique et par fréquence, qui incitent aux nouvelles lectures des documents, à la comparaison des pratiques scripturaires et de leur diffusion ou à l'étude des champs sémantiques, tout en exigeant la mise en place de méthodes adaptées au traitement des masses de données.

2 Cette journée d'études sera consacrée au retour d'expériences effectuées avec cet outil, des essais les plus ponctuels aux travaux les plus développés. L'objectif est, à la fois, d'inviter les chercheurs à se familiariser avec cette interface et d'en faire le point. Tous les chercheurs souhaitant partager leurs expérimentations sont conviés à y présenter leurs observations. Nous vous remercions de nous faire part de votre projet d'intervention avant le 30 octobre 2011 : marie-jose.gasse-grandjean@u-bourgogne.fr et eliana.magnani@u-bourgogne.fr.

\section{INDEX}

Mots-clés : CBMA 